\title{
PD-L1 expression and survival in p16-negative and -positive squamous cell carcinomas of the vulva
}

\author{
Bastian Czogalla ${ }^{1} \cdot$ Deborah Pham ${ }^{2} \cdot$ Fabian Trillsch $^{1} \cdot$ Miriam Rottmann $^{3}$. Julia Gallwas ${ }^{1}$ - Alexander Burges ${ }^{1}$. \\ Sven Mahner ${ }^{1} \cdot$ Thomas Kirchner $^{2} \cdot$ Udo Jeschke $^{1} \cdot$ Doris Mayr $^{2} \cdot$ Elisa Schmoeckel $^{2}$ (1)
}

Received: 27 December 2019 / Accepted: 2 January 2020 / Published online: 5 February 2020

(c) The Author(s) 2020

\begin{abstract}
Aim Programmed death-ligand 1 (PD-L1) has become a widely used predictive biomarker for therapy with checkpoint inhibitors in a variety of cancers. Here, we studied the expression of PD-L1 in squamous cell carcinomas of the vulva (SCCV) with regard to HPV status via its surrogate marker p16. Additionally, the status of PD-L1 and p16 were analyzed for prognostic information and potential correlation to tumor-infiltrating lymphocytes (TILs).

Methods PD-L1 was analyzed in 128 cases of SCCV using the tumor proportion score (TPS), the immune cell score (ICS) and the combined positive score (CPS). Cases were immunostained for p16 and analyzed for stromal TILs. PD-L1, p16, and TILs were compared to clinico-pathological parameters and patient's survival.

Results TPS $\geq 50 \%$ and CPS $\geq 50$ were correlated to a worse grading ( $p=0.028$ and $p=0.031$ ), but not to FIGO-stage. CPS $\geq 50$ was associated to a worse prognosis with overall survival $(p=0.021)$ but was not correlated to the progression-free survival. P16-positivity was correlated to a longer progression-free survival $(p=0.006)$ and overall survival $(p=0.023)$. PD-L1 expression was independent from p16 status. TILs $\geq 50 \%$ were present in $24 \%$ of the cases and were strongly correlated to PD-L1 (TPS $p=0.02$, ICS $p<0.001$, CPS $p=0.001$ ).

Conclusion Our data demonstrate that PD-L1 expression is frequent in SCCV and independent from p16 status. High PD-L1 expression was associated with an unfavorable outcome whereas p16-positivity turned out to be an independent positive prognostic factor.
\end{abstract}

Keywords Squamous cell carcinoma of the vulva $\cdot$ PD-L1 $\cdot$ p16 $~ T I L S$

Bastian Czogalla and Deborah Pham are joined first authors.

Electronic supplementary material The online version of this article (https://doi.org/10.1007/s00432-020-03126-9) contains supplementary material, which is available to authorized users.

Elisa Schmoeckel

Elisa.Schmoeckel@med.uni-muenchen.de

1 Department of Obstetrics and Gynecology, University Hospital, Ludwig Maximilians University (LMU), Munich, Germany

2 Institute of Pathology, Ludwig Maximilians University (LMU), Munich, Germany

3 Munich Cancer Registry, Bavarian Cancer Registry-Regional Centre Munich (LGL) at the University Hospital of Munich, Institute for Medical Information Processing, Biometry and Epidemiology, Ludwig Maximilians University (LMU), Munich, Germany

\section{Introduction}

Squamous cell carcinoma of the vulva (SCCV) is a relatively rare disease, accounting for $5 \%$ of all gynecologic malignancies (Siegel et al. 2016). However, incidence rates are increasing, particularly due to increase in younger women (Lai et al. 2014; Schuurman et al. 2013; Hampl et al. 2008). SCCV can be either human papillomavirus (HPV)-associated or -independent. Up to 25-40\% are linked to HPV-infection and the other group to chronic inflammatory and degenerative skin diseases, particularly lichen sclerosus (Gargano et al. 2012; Del Pino et al. 2013). Compared to oropharyngeal squamous cell carcinoma, the prognostic impact of HPV is considerably less established in SCCV. However, indications increase that HPV-linked SCCV have a more favourable prognosis (Sand et al. 2019; Lee et al. 2016). Mainstay of the therapy is surgery, which can be accompanied by radiation and/or chemo-radiation. Furthermore, 
advanced-stages have limited treatment options and there are only a few clinical trials for vulvar cancer. Therefore, target-based therapies and predictive biomarkers are needed to improve the clinical outcome of recurrent or metastatic disease.

Checkpoint inhibitors are among the most promising therapeutic approaches, being effective in a variety of cancers by leading to a strong immune-response against tumor cells by blocking PD1 or PD-L1 (Lyford-Pike et al. 2013). Immunostaining for PD-L1 has become a valid predictive biomarker that is routinely analyzed in several types of cancer. So far single case reports could demonstrate that PD-L1 inhibitors might be useful in SCCV (Shields and Gordinier 2019; Ott et al. 2019). Regarding different tumor types studies are controversial, whether PD-L1 expression is a prognostic marker too (Troiano et al. 2019; Wang et al. 2017; Wang 2019).

Recent studies about oropharyngeal squamous cell carcinomas and cervical cancer of the uterus indicate that PD-L1 expression is related to HPV status, suggesting that PD-L1 expression is increased in HPV-associated carcinomas (Mezache et al. 2015, 2017; Badoual et al. 2013; Lyford-Pike et al. 2013). Here, we assessed the HPV status in SCCVs via its surrogate marker p16.

Tumor-infiltrating lymphocytes (TILs) are an indicator of the immunogenic surveillance of cancer. Several studies could demonstrate a correlation of increased PD-L1 expression and numbers of TILs suggesting that both factor are cooperative (Meng et al. 2018). Furthermore, high percentages of TILs are associated with a better prognosis in several types of cancer including gynecologic cancers (Ruffini et al. 2009; Xu et al. 2019; Shah et al. 2011; Meng et al. 2018). However they have been hardly studied in SCCV.

This study aimed to investigate the potential prognostic impact of PD-L1 in p16-negative and p16-positive SCCVs and putative associations with stromal TILs.

\section{Materials and methods}

\section{Study group and clinical data}

The study population was generated consecutively and included 128 cases of SCCV, treated between 1994 and 2008 at the Department of Obstetrics and Gynecology, Ludwig-Maximilians-University, Munich, Germany. All tissue samples were derived from surgical resections, biopsies were excluded from the study group. Patient's age ranges from 20 to 96 (median age 71). Complete follow-up data were available for all cases with a median follow-up time of 66.7 months (standard deviation 58.9). 81 of the 128 patients (63\%) died during the follow-up period.

\section{Immunohistochemistry}

Immunohistochemical stains were performed using formalin-fixed paraffin-embedded (FFPE) tissues. To measure up to the heterogeneity of the PD-L1-staining, a whole tumor block was used for immunohistochemistry in each case. Sections were cut at $4 \mu \mathrm{m}$ from each paraffin block and mounted on SuperFrost Plus microscope slides (Menzel Gläser, Braunschweig, Germany), deparaffinized and stained with hematoxylin and eosin (HE). Immunohistochemistry was then performed for PD-L1 (clone SP263, Ventana, ready-to-use) and p16 (clone E6H4E6H4/p16 ${ }^{\text {Ink4a }}$, Ventana, ready-to-use). Immunohistochemistry was subjected to heat-induced epitope unmasking by heating with a pressure cooker and performed on a Ventana Benchmark XT autostainer (Ventana Medical Systems, Oro Valley, AZ) with the XT UltraView diaminobenzidine kit (Vector Laboratories, Burlingame, $\mathrm{CA}$ ) and hematoxylin counterstaining (Vector Laboratories, Burlingame, CA). Positive controls were included.

\section{Evaluation of PD-L1, p16 and TILs}

PD-L1 status was assessed using the Tumor proportion score (TPS) (Scheel et al. 2016), the Immune cell score (ICS) (Rosenberg et al. 2016) and the Combined positive score (CPS) (Agilent Dako 2018).

For the evaluation of PD-L1 expression in tumor cells, the TPS was used referring to $0=<1 \%, 1=\geq 1 \%$ and $<5 \%$, $2=\geq 5 \%$ and $<10 \%, 3=\geq 10 \%$ and $<25 \%, 4=\geq 25 \%$ and $<50 \%$ and $5=\geq 50 \%$. PD-L1 status in immune cells was evaluated by the ICS defined by ICS $0<1 \%$; ICS 1 $\geq 1 \%$ and $<5 \%$; ICS $2 \geq 5 \%$ and $<10 \%$; ICS $3 \geq 10 \%$. For evaluation of PD-L1 expression in both tumor cells and immune system, the CPS was used. The CPS is defined by the number of PD-L1 staining tumor cells and immune cells (lymphocytes, macrophages) divided by the total number of viable tumor cells, multiplied by 100 . Although, the result of the calculation can exceed 100, the maximum score is defined as CPS 100. PD-L1 staining was considered positive if the cell membrane was partially or completely stained, irrespective of the staining intensity. Cytoplasmic PD-L1 staining was disregarded.

P16-positivity was defined by a strong cytoplasmic and nuclear staining throughout the whole tumor on slide ("block" staining). Cases showing a weak or patchy staining were considered p16-negative.

TILs were assessed by HE staining. In this study, we analyzed the "stromal" TILs, which are defined by immune cells within the stroma of the tumor but without direct contact to the tumor cells. According to guidelines of the "TILs working group", the percentage of TILs covering the stroma of 
the tumor was estimated regarding the whole tumor-area on the slide (Salgado et al. 2015). The infiltration of TILs included lymphocytes, plasma cells and macrophages. Granulocyte-rich areas and necrosis were disregarded. First percentage of TILs were scored in 5\%-steps and then dichotomized into TILs $<50 \%$ and $\geq 50 \%$.

\section{Statistics}

For statistical analysis, the SPSS Statistics version 23 (SPSS Inc., Chicago, IL, USA) and SAS 9.4 (SAS software, Cary, NC, USA) were used. For testing proportional differences in univariate analysis, the Pearson's Chi-square test or the Fisher's exact test for qualitative variables. The survival curves were generated using the Kaplan-Meier technique and differences between these curves were tested by the log-rank test. For multivariate analyses, the Cox regression model for progression-free and overall survival (PFS, OS) was used. All tests were two-sided and the level of statistical significance was accepted at $p \leq 0.05$.

\section{Ethics}

All patients' data were fully anonymized, and the study was performed, according to the standards set in the Declaration of Helsinki 1975. The tumor tissue used was leftover material that had initially been collected for histopathological diagnostics. All diagnostic procedures have already been fully completed when samples were retrieved for the study. The current study was approved in writing by the Ethics Committee of the Ludwig-Maximilians-University, Munich, Germany (approval number 19-261). Authors were blinded for clinical information during experimental analysis.

\section{Results}

\section{Expression of PD-L1 correlates with clinico-pathological parameters}

PD-L1 positivity was observed in the majority of the cases: TPS $\geq 1 \%$ was found in $83 \%$, ICS $\geq 1 \%$ in $93 \%$, and CPS $\geq 10$ in $66 \%$. About $15 \%$ of the cases showed a high expression of PD-L1, defined by TPS $\geq 50 \%$ and CPS $\geq 50$. TPS $\geq 50 \%$ was significantly correlated to ICS $\geq 10 \%(p=0.026)$ and CPS $\geq 50(p<0.001)$. High PD-L1 expression (TPS $\geq 50 \%$ and CPS $\geq 50$ ) was significantly correlated to a worse grading ( $p=0.031$ resp. $p=0.033)$. However, there was no correlation to the FIGO-stage. Results of the evaluation of TPS, ICS, and CPS are listened in Table 2. The PD-L1 profile in association to the clinico-pathological parameters are listed in Tables 1 and 2 and illustrated in Figs. 1 and 2.
Table 1 P16-positivity (p16+), TILs $\geq 50 \%$ and high PD-L1 expression (TPS 5, ICS 3 and $\mathrm{CPS} \geq 50$ ) in correlation to patients characteristics and the overall survival $(n=128)$

\begin{tabular}{lllllll}
\hline Variables & Total (\%) & p16+ & TILs $\geq 50 \%$ & $\begin{array}{l}\text { PD-L1 TPS } 5 \\
(\geq 50 \%)\end{array}$ & $\begin{array}{l}\text { PD-L1 ICS 3 } \\
(\geq 10 \%)\end{array}$ & $\begin{array}{l}\text { PD_L1 } \\
\text { CPS } \geq 50\end{array}$ \\
\hline Total (\%) & & $50(39)$ & $31(24)$ & $24(19)$ & $57(45)$ & $25(20)$ \\
Age & & & & & \\
$\quad<70$ years & $57(45)$ & $32(64)$ & $16(52)$ & $14(58)$ & $25(44)$ & $14(56)$ \\
$\geq 70$ years & $71(55)$ & $18(36)$ & $15(48)$ & $10(42)$ & $32(56)$ & $11(44)$ \\
$p$ value & - & $<\mathbf{0 . 0 0 1}$ & 0.362 & 0.131 & 0.891 & 0.198 \\
Grading & & & & & & \\
G1 & $17(13)$ & $3(6)$ & $4(13)$ & $0(0)$ & $9(16)$ & $0(0)$ \\
G2 & $77(60)$ & $33(66)$ & $21(68)$ & $14(58)$ & $37(65)$ & $15(60)$ \\
G3 & $34(27)$ & $14(28)$ & $6(19)$ & $10(42)$ & $11(19)$ & $10(40)$ \\
$p$ value & - & 0.149 & 0.550 & $\mathbf{0 . 0 2 8}$ & 0.233 & $\mathbf{0 . 0 3 1}$ \\
FIGO & & & & & & \\
FIGO I & $36(28)$ & $18(36)$ & $12(39)$ & $5(21)$ & $16(28)$ & $6(24)$ \\
FIGO II & $52(41)$ & $19(38)$ & $11(36)$ & $9(38)$ & $23(40)$ & $8(32)$ \\
FIGO III & $31(24)$ & $9(18)$ & $7(23)$ & $9(38)$ & $13(23)$ & $10(40)$ \\
FIGO IV & $9(7)$ & $4(8)$ & $1(3)$ & $1(4)$ & $5(9)$ & $1(4)$ \\
$p$ value & - & 0.338 & 0.426 & 0.373 & 0.992 & 0.225 \\
Overall survival (univariate analysis) & & & & \\
$p$ value & & $<\mathbf{0 . 0 0 1}$ & 0.130 & 0.465 & 0.599 & 0.133 \\
\hline
\end{tabular}


Table 2 PD-L1 status of the study group (TPS, ICS and CPS)

\begin{tabular}{|c|c|c|c|c|c|c|}
\hline TPS & $0(<1 \%)$ & $1(\geq 1 \%)$ & $2(\geq 5 \%)$ & $3(\geq 10 \%)$ & $4(\geq 25 \%)$ & $5(\geq 50 \%)$ \\
\hline$N(\%)$ & $26(17.0)$ & $17(11.1)$ & $21(13.7)$ & $19(12.4)$ & $21(13.7)$ & $24(15.7)$ \\
\hline CPS & $0-<10$ & $10-<50$ & $50-<80$ & $80-100$ & & \\
\hline$N(\%)$ & $52(34.0)$ & $51(33.3)$ & $21(13.7)$ & $4(2.6)$ & & \\
\hline ICS & $0(<1 \%)$ & $1(\geq 1 \%)$ & $2(\geq 5 \%)$ & $3(\geq 10 \%)$ & & \\
\hline$N(\%)$ & $11(7.2)$ & 29 (19) & $31(20.3)$ & $57(37.3)$ & & \\
\hline
\end{tabular}

Table 3 Multivariate Cox regression analysis with (a) overall survival and (b) progression-free survival for CPS $(n=128)$

\begin{tabular}{lrll}
\hline Variables & $p$ value & Hazard ratios & 95\% Confidence interval \\
\hline (a) Overall survival & & & \\
Age $(<70$ versus $\geq 70)$ & $<0.001$ & 0.255 & $0.148-0.440$ \\
Grading $(\mathrm{G} 1$ versus G2/3) & 0.413 & 0.744 & $0.366-1.510$ \\
FIGO (I versus II-IV) & 0.005 & 0.415 & $0.225-0.766$ \\
CPS $(<50$ versus $\geq 50)$ & 0.021 & 0.535 & $0.314-0.910$ \\
(b) Progression-free survival & & & \\
Age $(<70$ versus $\geq 70)$ & 0.378 & 0.779 & $0.447-1.358$ \\
Grading $($ G1 versus G2/3) & 0.704 & 1.161 & $0.537-2.511$ \\
FIGO $($ I versus II-IV) & 0.417 & 0.777 & $0.422-1.431$ \\
CPS $(<50$ versus $\geq 50)$ & 0.157 & 0.626 & $0.327-1.197$ \\
\hline
\end{tabular}

\section{Expression of PD-L1 is correlated with overall survival}

Prognostic information was only evident in analysis with CPS while TPS and ICS did not provide significant results. High PD-L1 expression according to CPS $\geq 50$ was significantly correlated to a worse prognosis in multivariate Cox regression analysis with OS $(p=0.021$; Table 3$)$. However, CPS $\geq 50$ was not significant in univariate analysis $(p=0.133$; Table 1$)$. CPS $\geq 50$ was not correlated to the PFS ( $p=0.190$ for univariate and $p=0.157$ for multivariate analyses; Table 3 ).

Focusing on p16-negative cases only $(n=78)$ CPS $\geq 50$ showed a trend to potentially shorter OS in multivariate Cox regression analysis $(p=0.071)$.

\section{Status of p16 correlates with clinico-pathological parameters and affects the progression-free and overall survival}

P16-positivity was found in 50 (39\%) and p16-negativity in 78 cases (61\%) (Supplementary Fig. 1). P16-positivity was significantly correlated to the patient's age $(p<0.001)$ but not to FIGO-stage or grading (Table 1). P16-positivity was significantly correlated to a longer PFS and OS in both univariate (PFS $p=0.004$, OS $p<0.001$ ) and multivariate analyses (PFS $p=0.006$, OS $p=0.023$; Table 4, Fig. 3, Supplementary Fig. 2).
Status of p16 was independent of PD-L1 expression regarding TPS $5(p=0.290)$, ICS $3(p=0.591)$ and CPS $\geq 50$ $(p=0.176)$.

\section{Stromal TILs are associated with expression of PD-L1}

Stromal TILs $\geq 50 \%$ were found in 31 cases (24\%; Table 1, Fig. 2). TILs $\geq 50 \%$ were significantly associated to a high PD-L1 expression using all three scores: $p=0.02$ for TPS, $p<0.001$ for ICS 3 , and $p=0.001$ for CPS $\geq 50$. Stromal TILs $\geq 50 \%$ were not correlated to FIGO-stage, grading; patients age or to patients' overall survival (Table 1) nor to the status of $\mathrm{p} 16(p=0.394)$.

\section{Discussion}

We herein report that PD-L1 positivity is a frequent finding in SCCV. The majority of the study population showed a weak to moderate PD-L1 immunoreactivity in tumor cells and immune cells (TPS $\geq 1 \%$ in $83 \%$ and ICS $\geq 1 \%$ in $93 \%$ of the study group). PD-L1 expression in tumor cells was concordant to the expression in immune cells. TPS was significantly correlated to the ICS $(p=0.026)$ and strongly to the CPS $(p<0.001)$. High PD-L1 expression (TPS $\geq 50 \%$ and CPS $\geq 50$ ) was observed in about $15 \%$ and was associated with a worse grading, but was independent from FIGO-stage and was also found in early cancer stages. 
Fig. 1 Squamous cell carcinoma of the vulva showing high expression of PD-L1 in the tumor cells (PD-L1-positivity in $95 \%$ of the tumor cells; TPS $5, \mathrm{CPS} \geq 100$ ) and moderate expression of PD-L1 in stromal immune cells (ICS 2). $\mathbf{c}$ and $\mathbf{d}$ Refer to the inset in b. a HE, b-d PD-L1. Scale bars a and b $2.0 \mathrm{~mm}, \mathbf{c} 200 \mu \mathrm{m}, \mathbf{d} 100 \mu \mathrm{m}$
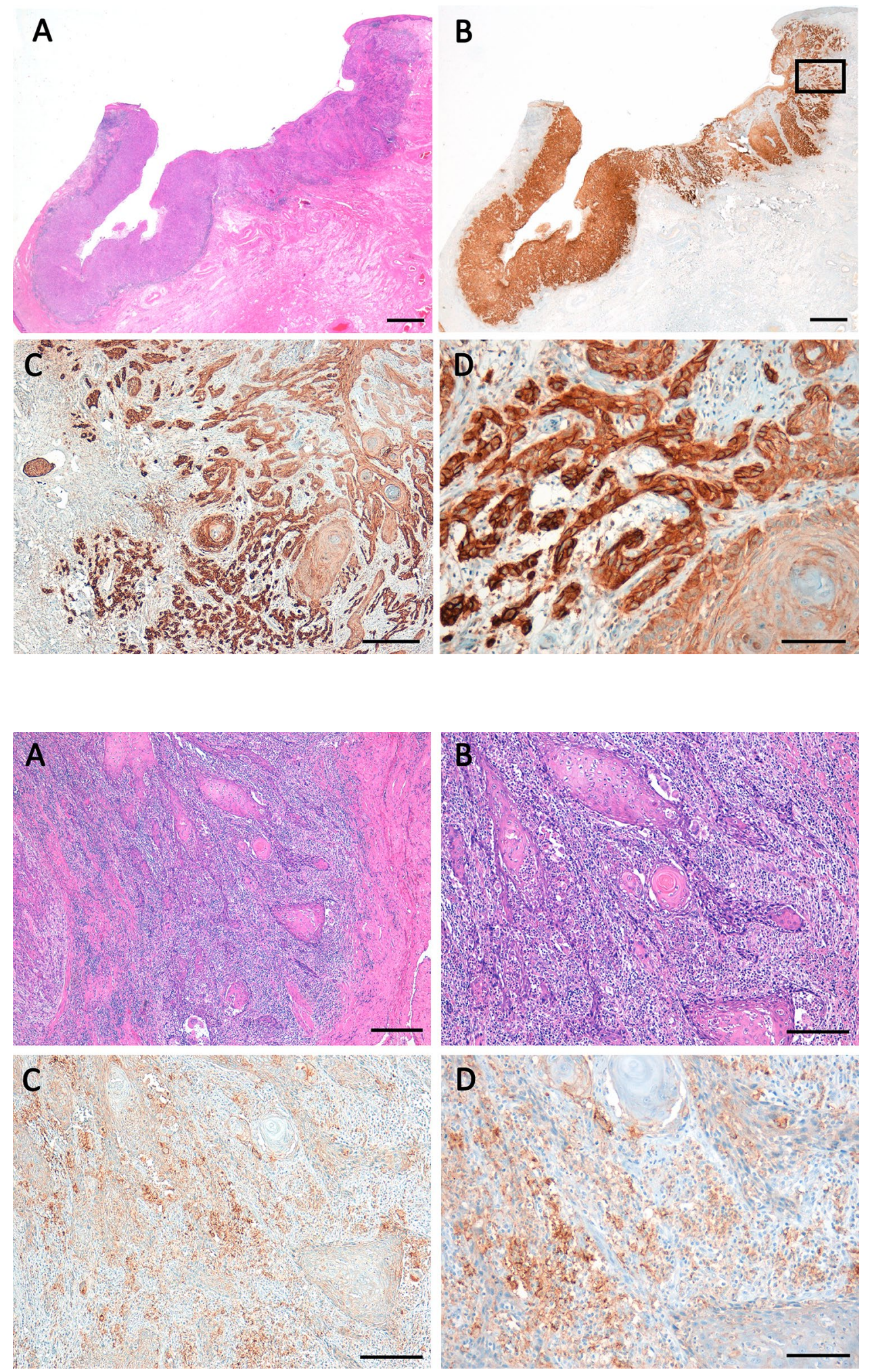

Fig. 2 Squamous cell carcinoma of the vulva with high percentage of stromal TILs (TILs $\geq 50 \%$ ) in $\mathbf{a}$ and $\mathbf{b}$ (HE) associated to high PD-L1 expression $\mathbf{c}, \mathbf{d}$ in stromal immune cells (ICS 3 ) and moderate PD-L1 expression in tumor cells (TPS 4 , CPS $\geq 50<80$ ). Scale bars a $400 \mu \mathrm{m} ; \mathbf{b}$ and $\mathbf{c} 200 \mu \mathrm{m} ; \mathbf{c}$ $100 \mu \mathrm{m}$
Little is known about the PD-L1 status in SCCV, but high frequency of PD-L1 expression was also reported by a few other studies (Choschzick et al. 2018; Hecking et al. 2017; Thangarajah et al. 2019). Currently clinical data about checkpoint-inhibitor therapy in SCCV are limited, although responsiveness was reported for single cases (Shields and Gordinier 2019; Ott et al. 2019). With regard to locally advanced, recurrent or metastatic courses of disease, a 
Fig. 3 Overall survival for the status of $\mathrm{p} 16(n=128$, $p<0.001$ )
Table 4 Multivariate Cox regression analysis with (a) overall survival and (b) progression-free survival for p16 $(n=128)$

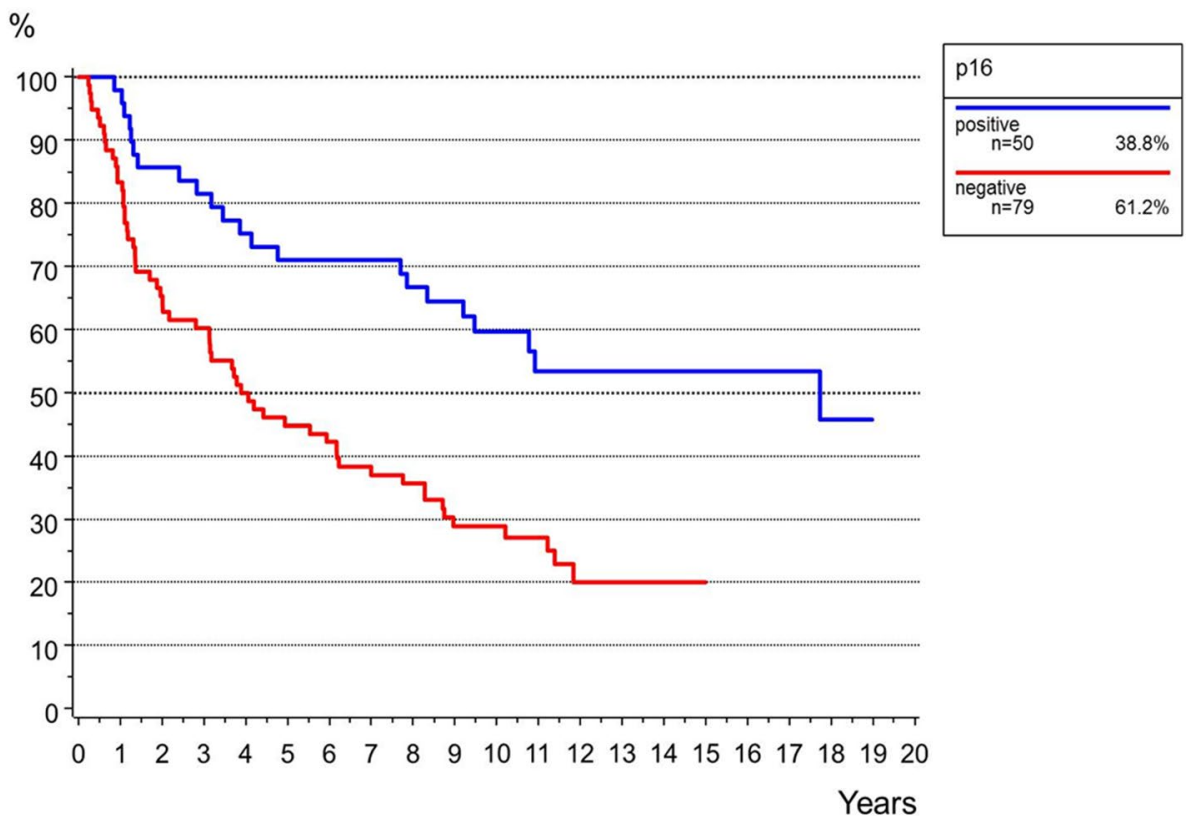

\begin{tabular}{lrll}
\hline Variables & $p$ value & Hazard ratio & $95 \%$ Confidence interval \\
\hline (a) Overall survival & & & \\
Age $(<70$ versus $\geq 70)$ & $<0.001$ & 0.339 & $0.195-0.589$ \\
Grading (G1 versus G2/3) & 0.139 & 0.590 & $0.293-1.186$ \\
FIGO (I versus II-IV) & 0.006 & 0.420 & $0.227-0.776$ \\
p16 (positive versus negative) & 0.023 & 0.550 & $0.329-0.920$ \\
(b) Progression-free survival & & & \\
Age $(<70$ versus $\geq 70)$ & 0.844 & 1.059 & $0.600-1.859$ \\
Grading (G1 versus G2/3) & 0.728 & 0.874 & $0.409-1.868$ \\
FIGO (I versus II-IV) & 0.486 & 0.805 & $0.437-1.482$ \\
p16 (positive versus negative) & 0.006 & 0.408 & $0.215-0.771$ \\
\hline
\end{tabular}

putative therapeutic response to checkpoint inhibitors should be verified in prospective treatment studies.

Many studies aimed to determine the prognostic impact of PD-L1 expression on the patient's survival. Regarding different cancer entities the prognostic value of PD-L1 is controversial (Wang 2019; Wang et al. 2017; Troiano et al. 2019). In this study, the CPS which combines the expression of tumor cells and immune cells, seemed to provide prognostic information for SCCV, while TPS and ICS did not correlate with the patient's outcome. High CPS was associated to a significant shorter OS $(p=0.021)$, although high CPS failed to be correlated to the PFS $(p=0.157)$. By now the prognostic impact of PD-L1 in SCCV was only analyzed in a few studies. According to Sznurkowski et al., PD-L1 expression in immune cells indicates a better prognosis (Sznurkowski et al. 2017), whereas PD-L1 expression in tumor cells was associated to worse outcome by Hecking et al. (2017). In addition, focusing p16-negative cases only high PD-L1 expression tended to correlate with a worse OS in our study population $(p=0.071)$. Correlation of PD-L1 expression with HPV-negative SCCV and poor outcome was also reported by Hecking et al. (2017).

Concurring with the expected frequency, p16-positivity was found in $39 \%$ of the cases, indicating a HPV-associated carcinogenesis. In this study, the status of p16 turned out to be an independent positive prognostic factor for SCCV. According to the 4th WHO classification, the prognostic impact of the HPV status is still considered to be unclear (Del Pino et al. 2013). However, indications increase that HPV-association is a positive predictive factor for SCCVs (Lee et al. 2016; Horne et al. 2018). Regarding oropharyngeal squamous cell cancer, several studies could verify p16 as a reliable surrogate marker for HPV-association (Prigge et al. 2017; Ma and Lewis 2012; Tan et al. 2016). However, it seems to be of interest that overexpression of p16 was also found in single cases of HPV-negative SCCV (Sznurkowski 
et al. 2016). Usually positive p16-staining correlates with oncogenic HPV infection by inactivation of the retinoblastoma protein via the viral E7 oncoprotein, but there are also HPV-independent mechanisms resulting in p16 expression (Riethdorf et al. 2004). Additionally, there may be differences in the definition of p16-positive. Only a strong "block" staining should be considered positive.

Finally, our data indicate that expression of PD-L1 is independent from the status of p16 in SCCV. Similar results have been published by Choschzick et al. (2018) and Thangarajah et al. (2019), indicating that PD-L1 expression is HPV-independent in SCCVs. These findings are supported by investigations on oropharyngeal SCCs that could show no correlation of the HPV-status and PD-L1 (Kim et al. 2016; Hong et al. 2019). Otherwise, PD-L1 was correlated to HPVnegativity in SCCVs too (Hecking et al. 2017). Thus, additional functional studies are needed to clarify the role HPV plays in PD-L1 induction.

TILs are discussed to be a reflecting indicator to the immune response of cancer. High numbers of TILs are believed to be associated with a better prognosis for many tumor entities (Badalamenti et al. 2018). Expression of PD-L1 was strongly associated to the amount of TILs in our cohort of SCCVs. This is reported for several different cancer types and is based on model that TILs may mediate PD-L1 expression in tumor cells by interferon release (Abiko et al. 2015; Badalamenti et al. 2018). However, TILs were not of prognostic importance in our cohort of vulvar SCCs. Further characterization of the infiltrate of TILs in SCCV will be needed to validate TILs as promising marker to select patients who may benefit from specific immunologic treatments.

In summary, our results show that PD-L1 positivity is a frequent finding in SCCV. PD-L1 immunoreactivity seems to be independent from p16 status and tends to indicate a worse outcome whereas p16 positivity turned out to be an independent positive prognostic marker.

Acknowledgements Open Access funding provided by Projekt DEAL.

Author contributions ES designed the study, researched, analyzed the data and wrote; BC wrote and reviewed the manuscript; DP researched and analyzed the data; MR supported the statistical analyses; DM, UJ, FT, JG, SM and TK analyzed and interpreted the data, edited and reviewed the manuscript. All authors gave final approval for publication; ES takes full responsibility for the work as a whole, including the study design, access to data, and the decision to submit and publish the manuscript.

Funding No funding was received.

\section{Compliance with ethical standards}

Conflict of interest S.M. received research support, advisory board, honoraria and travel expenses from AstraZeneca, Clovis, Medac, MSD, PharmaMar, Roche, Sensor Kinesis, Tesaro and Teva. F.T. de- clares research support, advisory board, honoraria and travel expenses from AstraZeneca, Medac, PharmaMar, Roche and Tesaro. J. G. received honoraria for lectures from MSD and Roche.

Ethical approval All patients' data were fully anonymized, and the study was performed according to the standards set in the Declaration of Helsinki 1975. The current study was approved in writing by the Ethics Committee of the Ludwig-Maximilians-University, Munich, Germany (approval number 19-261).

Open Access This article is licensed under a Creative Commons Attribution 4.0 International License, which permits use, sharing, adaptation, distribution and reproduction in any medium or format, as long as you give appropriate credit to the original author(s) and the source, provide a link to the Creative Commons licence, and indicate if changes were made. The images or other third party material in this article are included in the article's Creative Commons licence, unless indicated otherwise in a credit line to the material. If material is not included in the article's Creative Commons licence and your intended use is not permitted by statutory regulation or exceeds the permitted use, you will need to obtain permission directly from the copyright holder. To view a copy of this licence, visit http://creativecommons.org/licenses/by/4.0/.

\section{References}

Abiko K, Matsumura N, Hamanishi J, Horikawa N, Murakami R, Yamaguchi K, Yoshioka Y, Baba T, Konishi I, Mandai M (2015) IFN-gamma from lymphocytes induces PD-L1 expression and promotes progression of ovarian cancer. Br J Cancer 112:1501-1509

Agilent Dako (2018) PD-L1 IHC 22C3 pharmDx Interpretation Manual-Urothelial Carcinoma. https://www.agilent.com/cs/libra ry/usermanuals/public/29276_22C3_pharmdx_uc_interpreta tion_manual_us.pdf

Badalamenti G, Fanale D, Incorvaia L, Barraco N, Listi A, Maragliano R, Vincenzi B, Calo V, Iovanna JL, Bazan V, Russo A (2018) Role of tumor-infiltrating lymphocytes in patients with solid tumors: can a drop dig a stone? Cell Immunol 343:103753

Badoual C, Hans S, Merillon N, Van Ryswick C, Ravel P, Benhamouda N, Levionnois E, Nizard M, Si-Mohamed A, Besnier N, Gey A, Rotem-Yehudar R, Pere H, Tran T, Guerin CL, Chauvat A, Dransart E, Alanio C, Albert S, Barry B, Sandoval F, Quintin-Colonna F, Bruneval P, Fridman WH, Lemoine FM, Oudard S, Johannes L, Olive D, Brasnu D, Tartour E (2013) PD1-expressing tumor-infiltrating $\mathrm{T}$ cells are a favorable prognostic biomarker in HPV-associated head and neck cancer. Cancer Res 73:128-138

Choschzick M, Gut A, Fink D (2018) PD-L1 receptor expression in vulvar carcinomas is HPV-independent. Virchows Arch 473:513-516

Del Pino M, Rodriguez-Carunchio L, Ordi J (2013) Pathways of vulvar intraepithelial neoplasia and squamous cell carcinoma. Histopathology 62:161-175

Gargano JW, Wilkinson EJ, Unger ER, Steinau M, Watson M, Huang Y, Copeland G, Cozen W, Goodman MT, Hopenhayn C, Lynch CF, Hernandez BY, Peters ES, Saber MS, Lyu CW, Sands LA, Saraiya M (2012) Prevalence of human papillomavirus types in invasive vulvar cancers and vulvar intraepithelial neoplasia 3 in the United States before vaccine introduction. J Low Genit Tract Dis 16:471-479

Hampl M, Deckers-Figiel S, Hampl JA, Rein D, Bender HG (2008) New aspects of vulvar cancer: changes in localization and age of onset. Gynecol Oncol 109:340-345 
Hecking T, Thiesler T, Schiller C, Lunkenheimer JM, Ayub TH, Rohr A, Condic M, Keyver-Paik MD, Fimmers R, Kirfel J, Kuhn W, Kristiansen G, Kubler K (2017) Tumoral PD-L1 expression defines a subgroup of poor-prognosis vulvar carcinomas with non-viral etiology. Oncotarget 8:92890-92903

Hong AM, Ferguson P, Dodds T, Jones D, Li M, Yang J, Scolyer RA (2019) Significant association of PD-L1 expression with human papillomavirus positivity and its prognostic impact in oropharyngeal cancer. Oral Oncol 92:33-39

Horne ZD, Dohopolski MJ, Pradhan D, Bhargava R, Edwards RP, Kelley JL, Comerci JT, Olawaiye AB, Courtney-Brooks MB, Bockmeier MM, Berger JL, Taylor SE, Sukumvanich P, Beriwal S (2018) Human papillomavirus infection mediates response and outcome of vulvar squamous cell carcinomas treated with radiation therapy. Gynecol Oncol 151:96-101

Kim HS, Lee JY, Lim SH, Park K, Sun JM, Ko YH, Baek CH, Son YI, Jeong HS, Ahn YC, Lee MY, Hong M, Ahn MJ (2016) Association between PD-L1 and HPV status and the prognostic value of PD-L1 in oropharyngeal squamous cell carcinoma. Cancer Res Treat 48:527-536

Lai J, Elleray R, Nordin A, Hirschowitz L, Rous B, Gildea C, Poole J (2014) Vulval cancer incidence, mortality and survival in England: age-related trends. BJOG 121:728-738

Lee LJ, Howitt B, Catalano P, Tanaka C, Murphy R, Cimbak N, DeMaria $\mathrm{R}, \mathrm{Bu}$ P, Crum C, Horowitz N, Matulonis U, Viswanathan AN (2016) Prognostic importance of human papillomavirus (HPV) and p16 positivity in squamous cell carcinoma of the vulva treated with radiotherapy. Gynecol Oncol 142:293-298

Lyford-Pike S, Peng S, Young GD, Taube JM, Westra WH, Akpeng B, Bruno TC, Richmon JD, Wang H, Bishop JA, Chen L, Drake CG, Topalian SL, Pardoll DM, Pai SI (2013) Evidence for a role of the PD-1:PD-L1 pathway in immune resistance of HPVassociated head and neck squamous cell carcinoma. Cancer Res 73:1733-1741

Ma C, Lewis J Jr (2012) Small biopsy specimens reliably indicate p16 expression status of oropharyngeal squamous cell carcinoma. Head Neck Pathol 6:208-215

Meng Y, Liang H, Hu J, Liu S, Hao X, Wong MSK, Li X, Hu L (2018) PD-L1 expression correlates with tumor infiltrating lymphocytes and response to neoadjuvant chemotherapy in cervical cancer. J Cancer 9:2938-2945

Mezache L, Paniccia B, Nyinawabera A, Nuovo GJ (2015) Enhanced expression of PD L1 in cervical intraepithelial neoplasia and cervical cancers. Mod Pathol 28:1594-1602

Mezache L, Magro C, Hofmeister C, Pichiorri F, Sborov D, Nuovo GJ (2017) Modulation of PD-L1 and CD8 activity in idiopathic and infectious chronic inflammatory conditions. Appl Immunohistochem Mol Morphol 25:100-109

Ott PA, Bang YJ, Piha-Paul SA, Razak ARA, Bennouna J, Soria JC, Rugo HS, Cohen RB, O’Neil BH, Mehnert JM, Lopez J, Doi T, van Brummelen EMJ, Cristescu R, Yang P, Emancipator K, Stein K, Ayers M, Joe AK, Lunceford JK (2019) T-cell-inflamed geneexpression profile, programmed death ligand 1 expression, and tumor mutational burden predict efficacy in patients treated with pembrolizumab across 20 cancers: KEYNOTE-028. J Clin Oncol 37:318-327

Prigge ES, Arbyn M, von Knebel Doeberitz M, Reuschenbach M (2017) Diagnostic accuracy of p16(INK4a) immunohistochemistry in oropharyngeal squamous cell carcinomas: a systematic review and meta-analysis. Int J Cancer 140:1186-1198

Riethdorf S, Neffen EF, Cviko A, Loning T, Crum CP, Riethdorf L (2004) p16INK4A expression as biomarker for HPV 16-related vulvar neoplasias. Hum Pathol 35:1477-1483

Rosenberg JE, Hoffman-Censits J, Powles T, van der Heijden MS, Balar AV, Necchi A, Dawson N, O’Donnell PH, Balmanoukian A, Loriot Y, Srinivas S, Retz MM, Grivas P, Joseph RW, Galsky
MD, Fleming MT, Petrylak DP, Perez-Gracia JL, Burris HA, Castellano D, Canil C, Bellmunt J, Bajorin D, Nickles D, Bourgon R, Frampton GM, Cui N, Mariathasan S, Abidoye O, Fine GD, Dreicer R (2016) Atezolizumab in patients with locally advanced and metastatic urothelial carcinoma who have progressed following treatment with platinum-based chemotherapy: a single-arm, multicentre, phase 2 trial. Lancet 387:1909-1920

Ruffini E, Asioli S, Filosso PL, Lyberis P, Bruna MC, Macri L, Daniele L, Oliaro A (2009) Clinical significance of tumor-infiltrating lymphocytes in lung neoplasms. Ann Thorac Surg 87:365-371

Salgado R, Denkert C, Demaria S, Sirtaine N, Klauschen F, Pruneri G, Wienert S, Van den Eynden G, Baehner FL, Penault-Llorca F, Perez EA, Thompson EA, Symmans WF, Richardson AL, Brock J, Criscitiello C, Bailey H, Ignatiadis M, Floris G, Sparano J, Kos Z, Nielsen T, Rimm DL, Allison KH, Reis-Filho JS, Loibl S, Sotiriou C, Viale G, Badve S, Adams S, Willard-Gallo K, Loi S, TILs Working Group International (2015) The evaluation of tumor-infiltrating lymphocytes (TILs) in breast cancer: recommendations by an International TILs Working Group 2014. Ann Oncol 26:259-271

Sand FL, Nielsen DMB, Frederiksen MH, Rasmussen CL, Kjaer SK (2019) The prognostic value of p16 and p53 expression for survival after vulvar cancer: a systematic review and meta-analysis. Gynecol Oncol 152:208-217

Scheel AH, Dietel M, Heukamp LC, Johrens K, Kirchner T, Reu S, Ruschoff J, Schildhaus HU, Schirmacher P, Tiemann M, Warth A, Weichert W, Fischer RN, Wolf J, Buettner R (2016) Harmonized PD-L1 immunohistochemistry for pulmonary squamous-cell and adenocarcinomas. Mod Pathol 29:1165-1172

Schuurman MS, van den Einden LC, Massuger LF, Kiemeney LA, van der Aa MA, de Hullu JA (2013) Trends in incidence and survival of Dutch women with vulvar squamous cell carcinoma. Eur J Cancer 49:3872-3880

Shah W, Yan X, Jing L, Zhou Y, Chen H, Wang Y (2011) A reversed $\mathrm{CD} 4 / \mathrm{CD} 8$ ratio of tumor-infiltrating lymphocytes and a high percentage of $\mathrm{CD} 4(+) \mathrm{FOXP} 3(+)$ regulatory $\mathrm{T}$ cells are significantly associated with clinical outcome in squamous cell carcinoma of the cervix. Cell Mol Immunol 8:59-66

Shields LBE, Gordinier ME (2019) Pembrolizumab in recurrent squamous cell carcinoma of the vulva: case report and review of the literature. Gynecol Obstet Investig 84:94-98

Siegel RL, Miller KD, Jemal A (2016) Cancer statistics, 2016. CA Cancer J Clin 66:7-30

Sznurkowski JJ, Zawrocki A, Biernat W (2016) The overexpression of p16 is not a surrogate marker for high-risk human papilloma virus genotypes and predicts clinical outcomes for vulvar cancer. BMC Cancer 16:465

Sznurkowski JJ, Zawrocki A, Sznurkowska K, Peksa R, Biernat W (2017) PD-L1 expression on immune cells is a favorable prognostic factor for vulvar squamous cell carcinoma patients. Oncotarget 8:89903-89912

Tan LS, Fredrik P, Ker L, Yu FG, Wang Y, Goh BC, Loh KS, Lim CM (2016) High-risk HPV genotypes and P16INK4a expression in a cohort of head and neck squamous cell carcinoma patients in Singapore. Oncotarget 7:86730-86739

Thangarajah F, Morgenstern B, Pahmeyer C, Schiffmann LM, Puppe J, Mallmann P, Hamacher S, Buettner R, Alidousty C, Holz B, Scheel AH, Schultheis AM (2019) Clinical impact of PD-L1 and PD-1 expression in squamous cell cancer of the vulva. J Cancer Res Clin Oncol 145:1651-1660

Troiano G, Caponio VCA, Zhurakivska K, Arena C, Pannone G, Mascitti M, Santarelli A, Lo Muzio L (2019) High PD-L1 expression in the tumour cells did not correlate with poor prognosis of patients suffering for oral squamous cells carcinoma: a metaanalysis of the literature. Cell Prolif 52:e12537 
Wang L (2019) Prognostic effect of programmed death-ligand 1 (PDL1) in ovarian cancer: a systematic review, meta-analysis and bioinformatics study. J Ovarian Res 12:37

Wang Q, Liu F, Liu L (2017) Prognostic significance of PD-L1 in solid tumor: an updated meta-analysis. Medicine (Baltimore) 96:e6369

Xu X, Tan Y, Qian Y, Xue W, Wang Y, Du J, Jin L, Ding W (2019) Clinicopathologic and prognostic significance of tumor-infiltrating $\mathrm{CD} 8+\mathrm{T}$ cells in patients with hepatocellular carcinoma: a metaanalysis. Medicine (Baltimore) 98:e13923
Publisher's Note Springer Nature remains neutral with regard to jurisdictional claims in published maps and institutional affiliations. 